\title{
ФИНАНСИРОВАНИЕ ПРОЕКТОВ: ОСНОВНЫЕ ФОРМЫ ПРИВЛЕЧЕНИЯ ИНВЕСТИЦИЙ
}

\author{
И. Э. Гергаулов \\ Московский гуманитарный университет
}

Аннотация: Управляя инвестиционными проектами и реализуя их, предприятие поддерживает и улучшает функционирование и конкурентоспособность, тем самым увеличивая свою стоимость на рынке. Составной частью управления проектами является привлечение средств финансирования.

Ключевые слова: проект; финансирование; инвестиции; кредит; финансовое обеспечение

\section{PROJECT FINANCING: THE MAIN FORMS OF FUNDRAISING}

\author{
I. E. Gergaulov \\ Moscow University for the Humanities
}

Abstract: When managing and implementing investment projects, an enterprise maintains and enhances its performance and competitiveness, increasing thereby its market value. Fundraising constitutes an integral part of project management.

Keywords: project; financing; investments; credit; financial security

Реализация любого инвестиционного проекта предполагает необходимость его финансирования. Под финансированием проекта можно понимать процесс обеспечения его денежными средствами на протяжении всего горизонта его реализации.

Финансировать проекты можно из разных источников: фондов, прав на владение землей, патентов, образцов промышленной продукции и других.

Начиная работу над проектом, требующим инвестиций, нужно в первую очередь найти источники финансирования. Это самая важная цель, без достижения которой проект провалится еще на старте. Благодаря вовремя разработанной и грамотно выстроенной схеме финансирования проекта, 
можно сразу решить несколько важных задач планирования. К ним относятся: выявление баланса между займами и собственными вложениями; обеспечение выполнения проекта в полном объеме, согласно плану; снижение рисков; определение того, какие дальнейшие действия должны быть предприняты по отношению к инвестициям (налоговые выплаты, погашение кредита и др.). Денежные средства должны инвестироваться в проект на каждой стадии его реализации и вовремя покрывать все затраты. Таким образом, своевременное финансирование проекта выполняет важную задачу - гарантировать, что проект будет реализован согласно запланированному графику.

Вторая задача - это выстраивание оптимальной структуры финансирования.

Оптимизация преследует ряд целей. Она позволяет:

1. Избежать появления у инвестора лишних финансов, которые ему не нужны в данный момент и все равно не принесут никакой пользы и будут изъяты из инвестиционного процесса;

2. Минимизировать выплаты по кредитам и банковским ссудам; подбирать наилучшие условия кредитования и финансирования проектов в банке. Одним из критериев классификации источников финансирования считается их принадлежность инвесторам («отношения собственности») (Панова, 2012).

К собственным средствам инвестора относят его прибыль как физического или юридического лица; отчисления на амортизацию; доходы от благотворительности и других перечислений; страховые выплаты; иные финансовые накопления.

Под привлеченными средствами понимаются инвестиции, выплаченные государством. Последний из упомянутых источников финансирования инвестиционных проектов представляет собой прямое вложение денег в проект-победитель конкурса, или возвратную инвестицию, или инвестирование на том условии, что государство получает долю в управлении и прибылях от проекта. Для того чтобы пройти конкурс, план проекта должен отвечать следующим требованиям: проект окупится не более, чем за 3 года; проект позволит создать новые рабочие места (чем больше, тем лучше); он должен быть высокорентабельным; нужна гарантия того, что налоги по проекту будут выплачиваться вовремя. Средства для государственного финансирования проектов предоставляются из федеральных или из региональных запасов.

Средства, взятые из бюджета, - эта форма финансирования проектов предоставляется в виде ассигнований из федерального или регионального бюджета. Оно является частью программы инвестирования в новые проекты. 
Научные труды Московского гуманитарного университета 2018 № 5

Инвестиция в долг. В этом случае средства, которые выдаются на проект, необходимо будет вернуть, так как выданы они в форме займа. В роли кредиторов могут быть коммерческие банки, государство (оно может субсидировать новый бизнес), ипотечные банки, акционеры. Средства, выделенные для финансирования бизнес-проекта банком. Банк может выдать проекту кредит или занять деньги на долгий срок.

Бизнес-ангелы (ангельские инвестиции) - венчурный капитал как источник инвестиций. Представление проекта бизнес-ангелам, которые подбирают венчурные инвестиции для снабжения проекта.

Лизинг - согласно федеральному законодательству, это такое инвестирование, при котором материальное имущество передается в пользование получателю на некоторое время. Время пользования и размер оплаты оговариваются в договоре. Важным пунктом договора о лизинге является то, что при выполнении ряда условий и в ряде обстоятельств имущество в лизинге может быть выкуплено пользователем. Опыт многих стран показывает, что лизинговое инвестирование позитивно влияет на движение средств во время кризиса. Лизинг - это форма прямого финансирования проектов. Иначе говоря, получатель средств возмещает предоставителю инвестиции затраты и вознаграждает его напрямую.

Инвестиционный налоговый кредит возможен на территории России с момента введения поправок в Налоговый кодекс РФ. Этот кредит является платной услугой, обязательно возвращается и предоставляется только на определенный срок. За получение средств по такому кредиту взимаются проценты, которые равны 50-75\% от ставки рефинансирования Центрального Банка. Есть строго определенный список условий, при выполнении которых участники могут рассчитывать на финансирование проекта в форме инвестиционного налогового кредита: кредит в размере $30 \%$ от стоимости оборудования предоставляется на научное исследование, экспериментальную работу или техническое переструктурирование производства, если эти мероприятия направлены на включение в работу лиц с особыми потребностями и повышение экологической безопасности производства. Кредит, размер которого обговаривается отдельно, может быть предоставлен на внедрение инновационных технологий, исследование различных видов сырья и исходных материалов, внедрение новых разработок в этой области; Кредит в размере, который также обговаривается отдельно, выдается таким проектам, которые возникают в ответ на социальный или экономический заказ в конкретном регионе либо осуществляют важную работу с населением.

Финансирование проектов с помощью венчурных фондов за рубежом гораздо популярней, чем в России. Однако наша страна тоже постепенно осваивает венчурные фонды, и темп развития этого сектора инвестиционного 
бизнеса совпадает с темпом развития предпринимательства в целом. Количество российских венчурных фондов неуклонно растет. Большинство венчурных фондов предпочитают не делать ангельские инвестиции, дающие проекту хороший старт, а откладывать финансирование бизнес-проектов до момента, когда те уже упрочат свое положение на рынке. Специалисты РБК считают, что стране нужны такие фонды, которые будут использовать государственную поддержку и частный капитал и вкладываться в проекты на стадии их зарождения. Финансирование проектов с использованием банковского кредитования Инвестиционный кредит - это дополнительный вариант займа, который может позволить себе компания. Заём является целевым и берется для того, чтобы реализовать определенный проект. Банк инвестирует средства в организацию для того, чтобы она получила возможность для развития и смогла воплотить инновационные идеи при уже развернутом бизнес-процессе. Такой вариант финансирования проектов в банке может быть осуществлен в нескольких видах (Бой, 2014).

Стандартная инвестиция в виде кредита. Инвестируемая организация должна быть активной и приносящей прибыль. Этой прибыли должно быть достаточно, чтобы компания могла в перспективе погашать кредит. Он выдается на воплощение конкретных идей по развитию бизнеса или усовершенствованию рабочих процессов. Сумма кредита рассчитывается, исходя из текущих прибылей организации. Те бонусы, которые компания получит от будущего проекта, не рассматриваются при анализе ее заявки на инвестиционное кредитование. Она должна быть способна покрыть кредит за счет уже имеющихся ресурсов. Таким образом, риск финансирования проекта снижается как для банка, так и для самой компании. Даже если этот проект провалится, компания будет в состоянии отдать долг банку. Стандартное инвестиционное кредитование может помочь организации достичь следующих целей: обновить оборудование и оснащение; приобрести новую технику, транспорт или другие инструменты, которые помогут предприятию расти; расширить структуру, открыть новые филиалы, запустить новую производственную линию и т. п.

Проектное финансирование проектов. Данный вид кредитования отличается тем, что компания может погасить долг перед кредитором с помощью тех средств, которые она получит благодаря воплощению в жизнь проекта. Проект сам окупает себя, и при заключении договора не учитывается то, какие прибыли приносила организация до его начала. Проектное финансирование - это адресное вложение денег в инвестиционный проект. Оно целенаправленно и сопряжено с высоким уровнем риска, чем сильно отличается от предоставления синдицированных кредитов и работы венчурных фондов. Риск в финансировании проектов связан, прежде всего, с 
Научные труды Московского гуманитарного университета 2018 № 5

разработкой и реализацией нового продукта или услуги. К плюсам такого вида финансирования надо отнести простоту и меньший риск. Руководитель проекта работает не с большой группой инвесторов, а (как правило) только с одним, и этот инвестор вкладывает крупную сумму денег в достижение цели проекта. Говорить о том, что инвестиция является финансированием проекта, а не чем-то другим, можно только в следующих случаях: когда юридическое лицо финансирует проект, отдельный от него как в юридическом, так и в экономическом плане; когда это новый проект, а не предприятие, которое уже какое-то время существует; когда деньги, предоставленные инвестором, будут возвращены за счет прибылей от проекта, и доля инвестиций составляет 4/5 его активов; когда компания, осуществляющая финансирование проекта, не предоставляет никаких гарантий или обеспечения, либо они несопоставимы с финансовыми рисками; когда любая прибыль от проекта, на которую может рассчитывать инвестор, связана с его будущей реализацией.

Активы организации могут быть использованы как залог или обеспечение по проектному кредиту. В этой ситуации банк отнесется к клиенту с гораздо большим доверием, что, безусловно, сыграет в пользу финансирования проекта. Зачастую банки сами обозначают, что организация должна предоставить залог по кредиту. Таким образом, они снижают для себя риск сделки, которая может окупиться в будущем, а может и нет. Компания должна предоставить банку бизнес-план своего проекта. В нем необходимо зафиксировать прогнозируемую окупаемость и уровень ожидаемого дохода от реализации. В зависимости от этих данных, банк примет решение о том, какую сумму и на какой срок он готов выдать компании. Как составить инвестиционное предложение для привлечения денег в бизнес 3 основных вида проектного финансирования Инвестиция или кредит, в котором весь риск берет на себя заемщик (так называемый «кредит с полным регрессом на заемщика»).

Такое финансирование получают малорентабельные проекты. Инвестиция или кредит, где за все риски отвечает кредитор («кредит без регресса на заемщика»). Такое финансирование проектов подразумевает их перспективность и потенциальную прибыльность: инвестор готов пойти на риск ради проекта, который впоследствии может окупиться сторицей. Инвестиция или кредит, где риски распределены между участниками («кредит с ограниченным регрессом на заемщика»). Этот вид финансирования проектов встречается чаще всего. Обе стороны оказываются заинтересованными в успехе их общего дела, если обе они рискуют своими деньгами в случае его провала.

Финансирование инвестиционных проектов организаций, которые 
планируют строительство коммерческой недвижимости. В этом случае кредит выдается для постройки жилых помещений, торговых и складских площадей или любых других объектов, имеющих торговое или промышленное назначение. Компания обращается в банк для оформления заявки на кредит, когда строительство уже хотя бы начато. При подаче заявки нужно сопроводить ее документами: документами, определяющими форму владения землей, на которой идет строительство (аренда, собственность); разрешение на строительство; сметы по проекту. Компания, которая обращается за кредитом, должна и сама вложиться в строительные работы. Банки устанавливают процентные планки касательно личного включения заявителя в общий бюджет строительства. Чем эти планки выше, тем в лучшем положении оказывается заявитель (Воронцовский, 2014).

Любой проект, который только начинает воплощаться в жизнь, сопряжен с большим риском. Как бы четко ни был составлен план финансирования проекта и его реализации, жизнь всегда вносит свои коррективы.

\section{СПИСОК ЛИТЕРАТУРЫ}

Бой, Ж. (2014) Лучшее пособие от ведущих мировых компаний по проектному менеджменту. М. : АСТ ; Астрель. 160 с

Воронцовский, А. В. (2014) Инвестиции и финансирование. Методы оценки и обоснования. М. : Издательский дом Санкт-Петербургского государственного университета. 528 с.

Панова, Г. С. (2012) Внедрение проектного финансирования на государственном уровне. М. : Palmarium Academic Publishing. 256 с.

Дата поступления: 15.09.2018 2.

Гергаулов Илья Эдуардович - магистрант факультета экономики и управления Московского гуманитарного университета. Адрес: 111395, Pоссия, г. Москва, ул. Юности, д. 5. Тел.: 8(916) 171-75-65. Эл. адрес: gerik94@ mail.ru. Научный руководитель - к. э. н. Н. Ю. Аббас.

Gergaulov Ilya Eduardovich, Graduate Student, Faculty of Economics and Management, Moscow University for the Humanities. Postal address: 5, Yunosti St., Moscow, Russian Federation,111395. Tel.: +7 (916) 171-75-65. E-mail: gerik94@ mail.ru. Scientific Advisor - N. Yu. Abbas, Candidate of Economics. 


\section{Для цитирования:}

Гергаулов И. Э. Финансирование проектов: основные формы привлечения инвестиций [Электронный ресурс] // Научные труды Московского гуманитарного университета. 2018. № 5. URL: http://journals.mosgu.ru/trudy/ article/view/828 (дата обращения: дд.мм.гг.). DOI: 10.17805/trudy.2018.5.8 